\title{
Conditions on transfer in phonology
}

\author{
Björn Hammarberg
}

Recent years have witnessed revived interest in aspects of transfer in second language acquisition (SLA), manifested in an increasing number of articles, and in books bearing titles such as Language transfer in language learning (Gass-Selinker 1983/1992), Crosslinguistic influence in second language acquisition (Kellerman-Sharwood Smith 1986), and The role of the first language in foreign language learning (Ringbom 1987). A modern textbook on language transfer has appeared (Odlin 1989). However, relatively few researchers have attempted to re-explore transfer in the context of phonology acquisition ${ }^{1}$. This may seem strange, considering (a) the strong interest in phonology in earlier contrastive linguistics, and (b) the fact that those pioneers of interlanguage study in the 1970 s who considered transfer to be unimportant in L2 morphology and syntax acquisition, generally acknowledged its predominant role in the domain of L2 phonology.

At the same time it is clear that the workings of transfer in phonology, as in morpho-syntax, lexis, discourse etc., are subject to certain constraints, and that these must be understood and assessed if we are to account properly for the role of transfer in the development of interlanguage phonologies. Several such constraining factors have been suggested.

What I will attempt to do here is to review and discuss a number of factors which give rise to, condition and constrain transfer in L2 phonology acquisition, and to consider how they work together in specific cases. For illustration I will use data mainly from Hammarberg (1988), which is an investigation of the acquisition of Swedish phonology by adult German speakers at early stages.

The general theoretical view on language transfer I am adopting here comes close to that outlined by Færch and Kasper $(1980,1986,1987)$. They define transfer within an information-processing model as "a psycholinguistic procedure by means of which L2 learners activate their L1/Ln knowledge in developing or using their interlanguage" (1987: 112). It is the "developing" (or acquisitional) aspect more than the "using" (or communicational) aspect that will be focused on in this paper.

In practice, SLA researchers often seem to glide between the perspectives of transfer as a procedure and transfer as a product. This is not necessarily 


\section{Björn Hammarberg}

contradictory. Even if transfer is primarily taken to be an activity on the part of the learner, there is reason to consider cases of transfer at different levels of analysis: (a) at the level of strategy, with regard to the learner's plan of action to solve the problem of acquiring some specific regularity in L2; (b) at the level of execution, with regard to the event, or process of carrying out the strategy; and (c) at the level of solution, with regard to the product (as manifested in the learner's L2 performance) of the applied strategy (cf. Hammarberg 1988). Observations of the learner's solutions may permit us to draw conclusions about the underlying strategies and processes. When discussing from an empirical basis, it is often convenient to speak about "solutions" in a wide sense, implicitly including the learner activity which leads up to the resulting solution.

I think the distinctive character of transfer can best be defined at the level of strategy, adopting the notion of strategy proposed by Færch and Kasper (1980). In acquisition, then, transfer is a kind of, what these authors term, "psycholinguistic learning strategy", i.e. a strategy which the learner uses to form hypotheses about L2, the criterion of "transfer" being that it makes use of prior linguistic knowledge (in contrast to a purely "inductive" strategy which relies solely on the L2 intake). Apparently most cases of transfer in acquisition are of the "inferencing" type, in which the learner makes use of prior linguistic knowledge to interpret L2 intake. This is in contrast to "noninferencing" cases of transfer, where the learner applies prior knowledge in a deductive way in the absence of any relevant L2 intake. In their 1980 paper, Færch and Kasper let the term "transfer" cover both "interlingual" transfer (based on knowledge of a language other than L2, most commonly L1) and "intralingual" transfer (based on the interlanguage), arguing that the two are psycholinguistically alike. (Cf. also Færch - Kasper 1986: 56.) Without opposing this in principle, I will refer only to the interlingual cases in the present paper, especially since part of the purpose her is to examine the nature of the first-language influence. But it should be noted (as Færch and Kasper also do) that interlingual transfer may well co-occur or converge with reliance on prior L2 knowledge.

The matrix of Figure 1, then, shows in a schematic way the place of transfer within a typology of psycholinguistic learning strategies.

In the framework of Færch and Kasper, transfer is part of the learner's procedural knowledge, operating on his declarative knowledge. The occurrence of transfer in language use is sensitive to factors of attention and automatization. In a related framework, Bialystok and Sharwood Smith (1985) (cf. also Sharwood Smith 1986) make the "distinction between linguistic knowledge and the learner's control of that knowledge in real-time proces- 
learner's cues

L2 intake prior knowledge of L2

prior knowledge of $\mathrm{L} 1 / \mathrm{Ln}$ induction

$+$

$-$

Figure 1.

sing of utterances" (1985: 101, their italics). Even if these dimensions are of particular importance when dealing with language production and reception, they are also relevant in the acquisitional context, and we will find occasion to touch upon them in the following.

The literature on SLA displays various views as to what is transferred in the phonic domain: phonetic categories (e.g. Wode 1981, Flege 1987); phonological rules (e.g. Weinreich 1953, Eliasson 1982, Rubach 1984, Linell 1979); surface phonetic constraints (Eckman 1981a, 1981b); Stampean natural processes (Dziubalska-Kolaczyk 1987; Major 1987).

In spite of the diverse theoretical orientations which are reflected here, it is possible to derive some shared assumptions from recent research on SLA phonology about general types of requirements which have to be met for phonic transfer to take place. Especially, it is necessary to account for the matching of elements across languages, the degree to which various elements in L1 are liable to undergo transfer, and the relationship between transfer solutions and interlanguage development. In accordance with this, we may group the various conditions on transfer in phonology under the three broad headings of (a) perceived equivalence, (b) natural motivation, and (c) developmental relevance. I will comment on them in turn.

\section{Perceived equivalence}

The condition of perceived equivalence is met if the learner perceives an element (structure, category, rule etc.) in the target language and one in the native language as sufficiently similar to pass as equivalent. This was seen as the crucial condition in early contrastive linguistics, and it was central to Weinreich (1953) when he stated that phonic interference presupposes identification:

Interference arises when a bilingual identifies a phoneme in the secondary system with one in the primary system and, in reproducing it, subjects it to the phonetic rules of the primary language.

(Weinreich, 1953:14.) 
The subjective and gradual nature of the equivalence criterion should be stressed. The point that it is the learner himself who decides about equivalence, is implicit in the quoted passage from Weinreich, and it was a theoretical weakness in classical contrastive linguistics that one generally assumed, as a practical matter of method, that equivalencies could be established by the descriptive linguist on the basis of a native/target language comparison. In Wode's (1981) approach, the decision process is described as a matching procedure:

The input is L2 as spoken by the L2 environment to which the learner is exposed. L2 phonological targets are scanned for equivalencies and for nonequivalencies. There seems to be a crucial measure that separates the range of equivalencies from non-equivalencies. L2 elements which fall within this crucial range of equivalence are matched and substituted by their respective L1 equivalents. Those that fall outside this crucial range, undergo other developments.

(Wode 1981: 232)

An important point here is that cases of transfer are put in relation to cases where other strategies are applied. The clearest illustration of this in Wode's data is seen in the way English / $r$ / is handled by German child learners. Here, a transfer solution $[R]$ alternates and competes with a firstlanguage-acquisition-like solution $[\mathrm{w}]$. It follows from the quoted statement from Wode that a transfer strategy is assumed to take precedence over other strategies as soon as the equivalence criterion is met. But then it is also worth pointing out that the similarity scale must be understood as gradual, and that the learner may be more or less uncertain about his equivalence judgement. In other words, there is a dimension of plausibility (for the learner) connected with the equivalence criterion. The cited example with $/ \mathrm{r} /$ appears to be a borderline case, where a transfer and a non-transfer solution compete for plausibility. Likewise, two or more specific transfer solutions may compete for plausibility, since different elements in L1 may be likely candidates for identification with the L2 target. Examples of this are frequent. One illustrative case can be cited from an identification test (reported in Hammarberg 1988: 48) in which adult German beginning learners of Swedish had to listen to Swedish words and render them in German orthography. The long Swedish [ $\mathrm{t}$ ] (as in $d u$ ) was identified predominantly (i.e. in about $90 \%$ of the answers) with German $\ddot{u}$ whereas the short $[\Theta]$ displayed greater variation, the main variants being $\ddot{u} 42 \%, u 37 \%$, and $\ddot{o} 11 \%$. It thus appears that the learners tended to find a clear and plausible equivalent for [ $\mathrm{t}:]$, but that there were several competing candidates for $[\Theta]$. 
The compelling effect of equivalence classification on the shape of the learner's perceptual categories in L2 has been demonstrated by Flege (1987) in an experiment which suggests that an L2 sound which has a near-equivalent in L1 (French $/ u$ / for English speakers) is harder to master than one which lacks a near-equivalent (French $/ \mathrm{y} /$ ). According to Flege, equivalence classification will have the effect that the learner's perceptual norm for L2 will merge with the norm that he has established previously for the equivalent in L1, and if there is a slight discrepancy, the result will be incorrect. The acquisition of an L2 category which lacks an equivalent in L1 will, on the other hand, not be hindered by this bias. Flege also makes the point that basically the same strategy of equivalence classification functions as an adaptive mechanism for the monolingual child when working out perceptual norms for sound categories in L1 from the varying tokens that the child is exposed to.

The various levels of structure in language constitute another dimension which plays a part for equivalence judgments. What the learner identifies across languages and brings to bear on his perception and pronunciation in L2 may be phonetic, phonological, lexical, orthographical, morphological, syntactic etc. elements, and these various criteria may of course interact or compete in a given case. This complicates the matter of predicting learner solutions quite considerably. To my knowledge, the priorities that determine the learner's selective use of cues for equivalence judgments at different levels of structure have not been very thoroughly explored. A question is if and on what grounds such competing criteria for equivalence judgments can be ordered in a hierarchy of precedence. Clearly, factors such as type of previous L2 input and experience, acquisitional stage, instruction, performance task etc. will have an influence.

There is evidence that the learner's L2 pronunciation on a given point may vary depending on whether it represents a purely phonetically-based ("bottom-up") solution or some kind of conceptually-based ("top-down") solution, and that the learner's choice between these types is not random. In Hammarberg (1988), tests of identification and imitation with absolute beginners, designed so as to favour phonetically-based solutions, were combined with tests with picture-cards and free conversation with early-stage learners, which left room for conceptually-based solutions. These tasks produced different results on some points. For example, Swedish long [a:] which is phonetically a low, back, slightly rounded vowel, was identified and rendered predominantly as an o/o-type vowel in the phonetic tests with absolute beginners, whereas the early-stage learners in the picture test mostly pronounced it as a low, central, unrounded [a:]. The [o/o] variants can be 
explained as an association with German /o:/ on phonetic grounds, whereas the [a:] variant is obviously oriented to the German pronunciation of /a:/. In ordinary language use, there are various cues for learners of Swedish to classify [a:] as an /a:/, such as morphological and speech-style alternations between long [a:] and short [a], as well as spelling, all these forming bases for "top-down" interpretations of this vowel. Thus, the pronunciation [a:] can be understood as a "top-down" type of solution. However, there was some alternation of variants in the picture-test which can be traced to the fact that some words have close lexical form-equivalents in L1. The variant [a:] was predominant in the words radio 'radio' and blad 'leaf', which have formequivalents in German (Radio, Blatt), whereas a back vowel [a:] or [o:] was predominant in the words gata 'street' and barn 'child' where the corresponding German words are quite different in form (Straße, Kind).

A broad conclusion which is supported by these and other data in the same study is that these early-stage L2 learners tended to prefer a lexicallybased solution over a purely phonetically-based one whenever a close lexical form-equivalent was available in L1.

In terms of the typology of strategies discussed earlier, the "bottom-up", or phonetically based solutions seem to represent a strategy where the inductive element is stronger, and the "top-down" solutions strategies which are predominantly inferential or deductive. However, here again a scale of plausibility is involved. Obviously, the relative degree of influence of phonetic and conceptual cues over the learner's choice is variable. In an experiment with German learners' handling of the Swedish retroflex consonants [t d n] in a number of words (reported in Hammarberg 1985, 1988) it was shown that the learners' preference for a lexically-based pronunciation solution varied gradually along a scale which was well correlated with the degree of cross-language transparency of lexical form. The learners' pronunciations tended to reflect the form of L1 lexical equivalents if these were similar enough, but the weaker the formal similarity, the more often did a phonetically based solution occur.

There is also a diachronic aspect of this, in that the relative dominance of different cues may change as the learner advances in L2. I will come back to this below.

\section{Natural motivation}

It is known that not all phonological regularities in $\mathrm{L} 1$ have an equally strong tendency to be transferred by L2 learners. With some phenomena, transfer 
works in a virtually compulsory manner, whereas in other cases transfer occurs less consistently, and in still others, is not used at all. It appears that this is related to the way the phonological regularities function in the learner's L1, in that the learner cannot easily avoid carrying over those regularities which effectively constrain him as a speaker of L1. Defining, verifying and explaining this sector of transferable phonological regularities must thus be a special case of the wider task of explaining psychologically real regularities in phonology in general. This has been attempted in a second language context from various theoretical points of view. Rubach (1984), working within the framework of cyclic phonology, states that L1 rules are transferable if they are "postcyclic", "context-sensitive" and "automatic". Linell (1979), considering the psychological reality of rules on the basis of a typology of their functions, characterizes "articulatory reduction rules", "perceptual redundancy rules" and some "phonotactic rules" as transferable, as opposed to other phonotactic rules and "morphophonological rules proper". Dziubalska-Kolaczyk (1987) and Major (1987) have applied Stampe's theory of natural phonology (cf. e.g. Donegan-Stampe 1979) to L2 acquisition; here, the relevant constraints are derived from the ways in which the learner has, or has not, limited "natural processes" in his previous language acquisition, notably in L1.

There is not space here for a detailed comparison of these various approaches, but the general point should be made that despite the diversity of theoretical frameworks, the resulting hypotheses about transferabilitiy are not drastically different. The transferable phonological phenomena can be broadly characterized as low-level regularities, synchronically motivated by articulatory economy or established articulatory or perceptual routines in the language, not limited by morphological or other extra-phonetic conditions, and operating in an unconscious way in normal speech. By contrast, L1 regularities which are abstract, lack phonetic motivation and rather perform a morphological role in the language, allow morphological or lexical exceptions, and are easy for the speaker to focus attention on, will not be transferred on a regular basis into a second language.

If we consider various $\mathrm{L} 1$ regularities from the point of view of their possible phonetic naturalness, we may note that there are some which are clearly natural and others which are clearly unnatural, but also some which seem to have both natural and unnatural properties. If phonetically natural phenomena are liable to undergo transfer and the unnatural phenomena are not, then the question remains what will happen in "partially natural" cases. A few examples from my German-Swedish study may provide some illustration of this issue. 


\begin{tabular}{|c|c|c|c|c|}
\hline \#_C & \#_V & 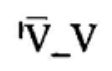 & 'VSon_V & 'V̌__V \\
\hline$(+)$ & $(+)$ & $(+)$ & $(+)$ & + \\
\hline$|z|$ & + & + & + & - \\
\hline+ & + & $(+)$ & + & + \\
\hline
\end{tabular}

$+=$ ample occurrence in the lexicon

$(+)=$ limited occurrence in the lexicon

- $=$ non-occurrence

Figure 2.

The well-known German final devoicing of obstruents (e.g. in Rad, klug, los) should be a good example of a natural regularity. This rule serves to give obstruent segments a phonetically preferred voiceless shape in the relatively demanding final position. It is exceptionless and not subject to particular morphological conditions.

Some less natural regularities in standard German can be found in the distributional pattern of $/ \mathrm{s} /, / \mathrm{z} /$ and $/ \mathrm{J} /$, particularly the limitations that appear to exist on the occurrence of $/ \mathrm{s} /$. The matrix in Figure 2 gives an overview of the occurrence of the three phonemes in some relevant environments.

In the initial preconsonantal position \#_C, $/ \mathrm{s} /$ is not used in native words and older loans, and for these words the pattern can be described as a neutralization in favour of $/ \mathrm{f} /$ (schnell, Stein). A phonological constraint against initial /s/ in German has been assumed (Wurzel 1981). But there is no phonetic motivation for such a constraint in the position \#_C. Generally, /s/ is a much more favoured segment than $/ \mathrm{f} /$ in the languages of the world (cf. Maddieson 1984), and there is nothing in the phonetic environment here that would bring forth $/ \mathrm{f} /$ rather than $/ \mathrm{s} /$. It is difficult to motivate phonetically why this neutralization occurs in initial position rather than finally or medially. I have argued (in Hammarberg 1988) that there is no justification for assuming a phonological constraint against initial preconsonantal $/ \mathrm{s} /$ in German. Historically, $/ \mathrm{J} /$ in this position derives from a restructuring of the phonemic system due to other changes, and not from any process of avoiding $/ \mathrm{s} /$. In recent loanwords, /s/ occurs in this position (Snob, Story). Consequently, what the regularity amounts to is a (certainly rather striking) structural pattern in the lexicon, but not a productive phonological rule or constraint. In terms of the naturalness concept I have used here, it is clearly unnatural.

In the initial prevocalic position \#_V, there is a similar neutralization between $/ \mathrm{s} /$ and $\mid z /$, favouring $/ \mathrm{z} /$ (sagen). Here it would seem more motivated 
to voice the sibilant in anticipation of the vowel. On the other hand, such a voicing rule does not apply to other obstruents in this position. In the case of $\mid s /$ and $/ z /$, as with other obstruents, the voiceless counterpart is generally a more favoured segment than the voiced one in the world's languages. In this position, too, /s/ occurs in recent loanwords, as in Sex [s-] vs. sechs [z-], which shows that there is not a fully productive constraint against $/ \mathrm{s} / \mathrm{here}$.

In some types of intervocalic position, such as ${ }^{\mathrm{V}}$ _ $\mathrm{V}$ (Wiese) and 'VSon_V (reisen, Linse), a contrast between $/ \mathrm{s} /$ and $/ \mathrm{z} /$ is maintained, but $/ \mathrm{z} /$ is more common than $/ \mathrm{s} /$. This has historical reasons, $/ z /$ deriving diachronically from the voicing of a simple $/ \mathrm{s} /$, and $/ \mathrm{s} /$ from a geminate $/ \mathrm{ss} /$. Voicing is supported phonetically by the voiced environment; on the other hand, other voiceless obstruents occur freely in this position. And voiced $/ z /$ is impossible in the position immediately following a stressed short vowel ('V̌_V, as in Wasser), where $/ \mathrm{s} /$ originates from a geminate. Intervocalic voicing, then, is not a widely applied process in German.

Thus, even if voicing in the positions \#_V, ' $\overline{\mathrm{V}}_{-} \mathrm{V}$ and 'VSon_V can be understood as in a sense "phonetically normal", and even if the dominance of $/ z /$ over $/ s /$ in these positions has resulted historically from productive assimilatory processes, the present-day pattern is at the same time "unnatural" in various respects.

Swedish like German has a voicing contrast in most obstruents, but there is no final devoicing rule. Also, Swedish uses /s/ freely in the environments described here. The issue then is to what extent the German learners of Swedish tend to transfer German sound patterns in the cases in point. It is instructive here to compare the profiles that emerge from two different performance-tasks: on the one hand an imitation test in which absolute beginners heard Swedish test words in a Swedish carrier phrase and were required to repeat them in a German carrier phrase, and on the other hand conversational speech recorded from early-stage learners. Imitation represents a case where the learner can more easily focus attention on the details of pronunciation. Frequent transfer errors here are evidence for a strong constraining factor; in this case, we should expect the corresponding transfer also to occur frequently in free speech, where the learner is less likely to focus attention on pronunciation details. On the other hand, lack of transfer in imitation is no strong evidence against the propensity for transfer in free speech; it is only evidence that transfer of this phonological regularity from L1 is easy to suppress. Table 1 displays the outcome of the two tasks.

The two tasks showed parallel results for the voiced final obstruents, and for the initial preconsonantal $/ \mathrm{s} /$. The former caused substantial difficulties, as expected. The substituted "error" variant was almost invariably a devoic- 
Table 1. Error percentages for some consonant structures in an imitation test and in free conversational speech with German learners of Swedish. 'Error \%' = average percentage of target-deviant tokens in 9-13 subjects in the imitation test and 5 subjects in the conversations. (Adapted from Hammarberg 1988)

\begin{tabular}{lllll}
\hline TL structure & \multicolumn{2}{c}{ imitation test } & \multicolumn{3}{c}{ conversation } \\
\cline { 2 - 5 } & error \% & $\begin{array}{l}\text { total } \\
\text { no. of } \\
\text { tokens }\end{array}$ & error \% & $\begin{array}{l}\text { total } \\
\text { no. of } \\
\text { tokens }\end{array}$ \\
\hline $\begin{array}{l}\text { Word-final voiced } \\
\text { obstruent }\end{array}$ & 58 & 52 & 91 & 234 \\
$\begin{array}{l}\text { [s] in crucial inter- } \\
\text { vocalic positions }\end{array}$ & 0 & 9 & 33 & 89 \\
$\begin{array}{l}\text { Initial prevocalic [s] } \\
\begin{array}{l}\text { Initial } \\
\text { preconsonantal [s] }\end{array}\end{array}$ & 0 & 9 & 15 & 205 \\
\hline
\end{tabular}

ed one, which means that the German devoicing rule was transferred. Initial preconsonantal $/ \mathrm{s} /$ was mastered without problems, and the subjects were not inclined to carry over the German $/ \mathrm{s} /$ pattern. However, for $/ \mathrm{s} /$ in those initial and intervocalic positions where $/ \mathrm{z} /$ is dominant in German, the results differ between the tasks. Although $/ \mathrm{s} /$ caused no difficulty at all in the imitation task, the /z/ pattern both pre- and intervocalically showed a weak but clear productivity in conversational speech. The "error" variants were voiced ones here.

These results suggest that there is a scale of transferability, ranging from those cases where a phonetically natural regularity in L1 transfers in a productive and compelling way, to those cases where an unnatural regularity in L1 does not transfer; and there are intermediate cases between these extremes, where an L1 regularity which is to some extent natural but not compelling for the L1 speaker, is transferred in a more weakly productive way. It will then be easier for the learner to suppress and more open to alternation with the target pattern.

In other words, these data suggest that it is in the intermediate cases that transferability is particularly sensitive to a factor of attention, or control (in the sense of Bialystok and Sharwood Smith). Hence we may hypothesize that "partially natural" phonological regularities in L1 tend to produce this type of non-compelling transferability, where attention and control have greater influence on the outcome. 


\section{Developmental relevance}

A further fundamental aspect is that transfer is a strategy which is applied in the course of an acquisitional process. In second language acquisition, transfer is a developmental phenomenon. Hence various factors which are relevant for interlanguage development will co-influence the use of transfer solutions.

A consequence of the condition of equivalence is that the application of transfer solutions is dependent on the learner's current state of development in L1 and L2. With adult learners, the state of acquaintance with L2 is crucial. Cross-language identifications and equivalence judgments will have to be based on those facts in the target language which the learner has so far had sufficient occasions to observe.

A case which illustrates the interaction of strategies in a developmental context is the German learners' handling of the Swedish retroflex consonants. In Central Swedish, sequences of $/ \mathrm{r} /$ plus a dental phoneme are regularly realized as single retroflex segments, so that $/ \mathrm{rt}, \mathrm{rd}, \mathrm{rs}, \mathrm{rn}, \mathrm{r} / \mathrm{be}-$ come [t, $\mathrm{d}, \mathrm{s}, \mathrm{n}, \mathrm{l}]$, respectively, as in karta 'map', bord 'table', kors 'cross', barn 'child', and pärla 'pearl'. There are various kinds of observable evidence from which learners may discover this phonological process in the target language, such as frequent morphophonemic alternations, spelling, and crossdialect variation. Occasional L1 cognate words forms with $/ \mathrm{r} /+$ dental are another source from which the underlying phonemic form may be inferred.

An imitation test with absolute beginners, where only the phonetic shape of the sound was available as a cue, showed that these subjects consistently rendered $[t, d, n]$ as dental $[t, d, n]$, and [s] with the close German phonetic equivalent $\left[\int\right]$ (as in Fisch). But in recorded conversational speech with earlystage learners, a variety of solutions occurred, which is shown in Table 2. These data come from a longitudinal study of five beginning learners during their first months of stay in Sweden. Conversation was recorded at Time 2, after about $11 / 2$ months, and Time 3 , after about $31 / 2$ months from arrival. (At Time 1, shortly after arrival, no Swedish conversation was yet possible.)

Let us first look at the way the learners handled the /rs/ words (which are pronounced in the target language with [s]). Here the learners at Time 2 most often used an unassimilated variant, $[\mathrm{rs}]$ (where $[\mathrm{r}]$ is a broad notation for various occurring r-types). In this case, the underlying phonemic form $/ \mathrm{rs} / \mathrm{had}$ apparently been identified, but the assimilation rule had not been put to use in the learners' own speech. The learners' pronunciation of /rs/ followed L1 rules. At Time 3, the same learners were using a single segment [s] or [ $\mathrm{J}]$ for $/ \mathrm{rs} /$ in conversation in the majority of instances. We may interpret this varia- 
Table 2. Rendering of the retroflexes in conversational speech by five German earlystage learners of Swedish: frequency distribution of variants. (From Hammarberg 1988)

\begin{tabular}{|c|c|c|c|c|c|}
\hline \multirow{2}{*}{$\begin{array}{l}\text { word } \\
\text { type }\end{array}$} & \multicolumn{4}{|c|}{ variants } & \multirow[t]{2}{*}{ total } \\
\hline & dental & $\mathrm{r}+$ dentala $^{\mathrm{a})}$ & $r+$ retrofle $x^{a, b},{ }^{2}$ & retroflex ${ }^{b}$ & \\
\hline \multicolumn{6}{|c|}{$\begin{array}{l}\text { time } 2 \\
\text { (2nd month) }\end{array}$} \\
\hline /rs/ & 1 & 14 & 5 & 6 & 26 \\
\hline$/ \mathrm{r} t /$ & 1 & 2 & & 1 & 4 \\
\hline$/ \mathrm{rd} /$ & 5 & 2 & & & 7 \\
\hline$/ \mathrm{rn} /$ & 1 & 3 & & 2 & 6 \\
\hline total & 8 & 21 & 5 & 9 & 43 \\
\hline \multicolumn{6}{|c|}{$\begin{array}{l}\text { time } 3 \\
\text { (4th month) }\end{array}$} \\
\hline /rs/ & 1 & 7 & 13 & 27 & 48 \\
\hline /rt/ & 7 & 5 & 1 & & 13 \\
\hline$/ \mathrm{rd} /$ & 2 & 12 & & 2 & 16 \\
\hline$/ \mathrm{rn} /$ & & 37 & & 1 & 38 \\
\hline total & 10 & 61 & 14 & 30 & 115 \\
\hline
\end{tabular}

a) $\mathrm{r}=$ uvular, vocalized or apical $\mathrm{r}$ variants.

b) In the case of /rs/, s-like and $\int$-like variants count as Retroflex.

tion of pronunciation as a shift conditioned by the type and extent of acquaintance with the target language. The imitation test shows that $[\delta]$ is the preferred, potentially available L 1 equivalent at the phonetic level. In the early conversations, this learner solution was overruled by a solution based on the discovery that /rs/ is the underlying form. In the later conversations, increased experience of spoken Swedish plus the available phonetic equivalent had apparently led the learners to establish a rule $/ \mathrm{rs} /->\left[\int, \mathrm{s}\right]$ in their own L2 speech. The variant " $r+$ Retroflex", which appears more than occasionally at both points of time, seems natural as a by-product of this ongoing process. It shows that the learners are cognizant of both the underlying $/ r /$ and the pronunciation with a retroflex fricative.

Looking at /rt, rd, rn/, we can see that the corresponding development has not taken place in these cases. The variants with retroflexes are rare here. Especially at Time 3, the solution " $r+$ Dental" predominates, showing that 
the learners have discovered this phonemic form. But there is no systematic use of the retroflexion rule. This can be explained by the absence of a close phonetic equivalent in L1 in these cases, like German [ $\left.\int\right]$ for Swedish [s], because for the retroflexion rule to get established, both the underlying form and the retroflex phonetic form would need to get supported by cues which the learner can grasp. The sound types $[t, d, \eta]$ are apparently still too difficult for the learners to master. So whereas both the conceptual and the phonetic cues interact to further the acquisitional process in the case of $/ \mathrm{rs} /$, the phonetic cues are not effective at these stages in the other cases.

As pointed out earlier, factors of attention and automatization may codetermine the extent to which an available transfer solution comes to play. This of course has a diachronic dimension. For example, a transfer solution which is suppressed at an initial stage when the learner focuses the problems of mastering new and unfamiliar elements, may reappear when the pronunciation of the items in L2 becomes routine. Instances of this can be found in my German-Swedish data, especially in a test of repeated picture-naming which was given to early-stage learners in recurrent sessions over a threemonth period. Thus, one learner had problems remembering the lexical item säng 'bed', German Bett, which exposed the problem of initial prevocalic /s/ mentioned above. As long as he could not recall the word without help, he usually pronounced it with the target-like /s/ although the experimenter had not called his attention to this detail, but as soon as he had managed to store the word firmly in his memory and could recall in spontaneously, he also settled on pronouncing it with a German-based initial $/ z /$. This regression in pronunciation appears natural if we consider that the transfer solution $\mathrm{I} / \mathrm{f}$ was the one that was automatized beforehand, in L1, whereas the inputbased solution $/ \mathrm{s} /$ was the one that was likely to require active attention at this stage.

Perhaps the most obvious evidence for the developmental role of transfer solutions is seen in the way L1-like learner solutions vary along a simplification/elaboration scale in acquisitional sequences over time. I will conclude this section with an example which illustrates this, viz. the handling of the final cluster/rj/ by German learners of Swedish in words like färg 'colour', torg 'market place' (see Hammarberg 1988: $153 \mathrm{ff}$. for full data and discussion). Word-final /rj/ (where [j] symbolizes a voiced palatal fricative or glide) is a difficult cluster for these learners, and one which violates L1 phonotactic constraints. A variety of solutions occur, the major types being the following: 
Learner solution

$$
\begin{array}{ll}
\text { Resulting } & \text { Degree of } \\
\text { syllable } & \text { structural } \\
\text { structure } & \text { simplification }
\end{array}
$$

(1) Reduction to [r] or [j]

(2) Syllabization: [ri]

VC\#

(3) Epenthetic vowel: [rja]

$\mathrm{V} \$ \mathrm{CV}$

(4) Final devoicing: [rç] VC\$CV

(5) The target variant: [ri] VCC\# VCC\#

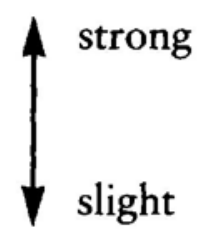

Two things are worth observing here. First, all these types, except the target variant, conform to the German phonotactic constraints and can thus be understood as transfer solutions. A further piece of evidence for their transfer status is the fact that $[\mathrm{r}]$ was generally pronounced by the learners in question with unmistakably German r-variants which could be more or less deviant from the target [r]. Second, the variants can be ordered along a scale from a higher to a lower degree of target structure simplification with respect to the resulting type of syllable structure, as shown above. With variant (4), final devoicing, the simplification merely consists in substituting a less marked segment for the voiced final [j].

These variants do not form a phonetic continuum from (1) to (5). Rather they represent alternative strategies for approximating the target structure within the limits of L1 phonological constraints. The learners, as it were, approach the target from alternative directions: see Figure 3.

But in addition to these main types, intermediate values of phonetic approximation to the target can be observed with some of the variants. Especially, there is a partially devoiced variant [rij] and a variant with a very weak epenthetic vowel [rj] $]$ : see Figure 4.

Table 3 shows the outcome for two learners, GS and WW, in an imitation test in which the learners were required to repeat Swedish test words containing final /rj/ (among various other items). The test was given to the

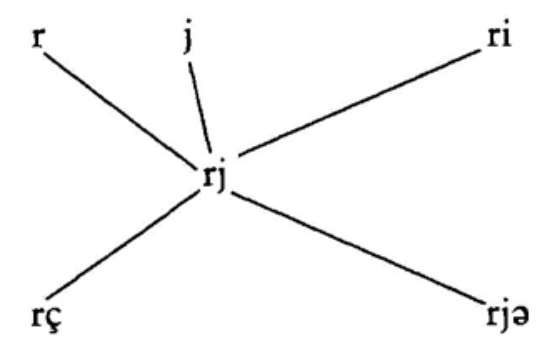

Figure 3. 


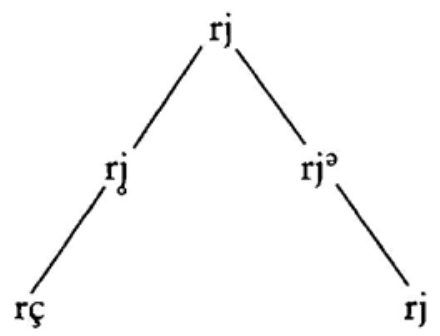

Figure 4.

same learners on three subsequent occasions, in the first, second and fourth month of exposure to Swedish, respectively. The most simplified variants, types (1) and (2) above, do not occur in this test. Those variants which occur have been ordered in the table along a simplification/elaboration scale, and have been given index values accordingly. Epenthesis has been ranked lower than final devoicing, which has lower rank than the target. An index score for each line in the table is obtained by multiplying the frequency of each variant with its index value and adding up the products (e.g. $3 \times 0+1 \times 2+$ $1 \times 3=5$ for WW at Time 1 ).

What the table shows is that there is a successive development over time in that the lower-ranked variants gradually decrease in frequency and the higher-ranked variants increase. This is also reflected by the index score which in this case increases over time. (More or less similar patterns were found also for other subjects and for other clusters.)

Table 3. Imitations of Swedish word-final /rj/ by two German learners: frequency distribution of variants. (Adapted from Hammarberg 1988)

\begin{tabular}{|c|c|c|c|c|c|c|c|c|}
\hline \multirow[t]{3}{*}{ subject } & \multirow[t]{3}{*}{ time } & \multicolumn{5}{|c|}{ variants with index values } & \multirow{3}{*}{$\begin{array}{l}\text { number } \\
\text { of test } \\
\text { items }\end{array}$} & \multirow{3}{*}{$\begin{array}{l}\text { index } \\
\text { scores }\end{array}$} \\
\hline & & rja & $\mathrm{rj}^{\mathrm{a}}$ & $\begin{array}{l}\text { rç } \\
\text { rj }\end{array}$ & $\begin{array}{l}\text { rç } \\
\text { rj̣ }\end{array}$ & rj & & \\
\hline & & 0 & 1 & 2 & 3 & 4 & & \\
\hline \multirow[t]{3}{*}{ GS } & 1 & 5 & & & & & 5 & 0 \\
\hline & 2 & 3 & & 1 & 1 & & 5 & 5 \\
\hline & 3 & 2 & & & 1 & 2 & 5 & 11 \\
\hline \multirow[t]{3}{*}{ WW } & 1 & 3 & & 1 & 1 & & 5 & 5 \\
\hline & 2 & 1 & 1 & & 1 & 2 & 5 & 12 \\
\hline & 3 & & 1 & 1 & 2 & 1 & 5 & 13 \\
\hline
\end{tabular}


The following explanation of this pattern can be offered. At the early stage, the learner is more inclined to resort to stronger simplification of the difficult target structure. Gradually, with increasing familiarity with the target language, this constraint gets looser, and the learner more often attempts less simplified variants. The learner solutions balance between the requirement of being processable for the learner and the requirement of matching the perceived target structure, whereby the most "advanced" solution that the learner can currently handle tends to be favoured. In this process, the phonological constraints of L1 tend to determine the form of the learner variants at each stage of development. This results in a variet of different solutions which are L1-oriented and form a successively changing dominance pattern conditioned by the developmental (simplification/elaboration) process.

\section{Summary and conclusion}

In this paper I have discussed several prerequisites for first-language transfer in the phonological domain of SLA. In recent SLA research, where the phenomenon of transfer has again become a matter of major concern, more theoretical attention has so far been given to it in syntax and other areas of language than in phonology, yet the issues that need to be addressed here are in part similar.

I have considered three major types of structural conditions on the occurrence of transfer. First, transfer is dependent on the learner's judgment that the phonological target in question is identifiable with some element or elements in $\mathrm{L} 1$ (the condition of perceived equivalence). A complication here is that this L1-L2 identification matter is often not a simple yes/no decision for the learner, but involves degrees of plausibility. There is room for competing solutions. A problem for research is to be able to predict the relative force of various cues that the learner may use for judging equivalence. In cases where a phonetically-based and a conceptually-based phonological solution compete, a preliminary principle is that the latter tends to take precedence. But as the example with /rs/ and / rt, $\mathrm{rd}, \mathrm{rn} /$ showed, a plausible identification cue can affect the result decisively.

Second, whether transfer occurs and to what extent it is compelling for the learner, is dependent on the phonetic naturalness and psychological reality of the categories or regularities in L1 which are at issue, the principle being that those regularities which constrain the learner as a speaker of L1 are difficult for him to avoid in L2 (the condition of natural motivation). 
Defining the kind of phonetically motivated phenomena which meet this criterion in the phonological domain is a task for phonetic and phonological theory in general, and here SLA research can supply evidence. However, naturalness in this sense is not an all-or-none concept; specific phonological regularities may be natural in part. Apparently we have a scale of intermediate cases between natural and unnatural, where factors of automatization and attention are more liable to influence the extent to which transfer occurs in learner performance.

Third, transfer functions as part of a developmental process, and the applicability of specific transfer solutions is dependent on the learner's current state of development in (L1 and) L2 (the condition of developmental relevance). As the learner becomes more acquainted with $\mathrm{L} 2$, the basis for a particular transfer solution may shift. This will affect the dominance pattern of competing solutions. Learners solutions may be understood to represent the current balance point between being processable and matching the target as well as possible. As the learner becomes more skilful in handling problematic phonetic structures and in processing them automatically, some transfer solutions will lose their motivation and get abandoned. Especially, in some cases it can be seen that different L1-oriented solutions succeed each other over time, changing along a simplification/elaboration continuum.

The emphasis here has been on the structural prerequisites for transfer, and their interaction with skill factors have been touched upon more briefly. Yet it is clear enough that they do interact, and that an understanding of the structural conditions on transfer must form an essential part of a theory of L2 skill development.

What has been defined here as conditions on transfer are not prerequisites for some general tendency to make use of L1 knowledge, but conditions that govern the applicability of the one or the other specific transfer solution. A main point here has been the attempt to show that each of the three basic conditions that $\mathrm{I}$ have identified in its turn contains a complex of factors which condition the use of competing variants and make transferability in each case a gradual phenomenon. Thus the interplay of such factors codetermines the variation of learner solutions which is so characteristic of interlanguages. A more thorough exploration and assessment of how these various factors interact and compete in specific cases would aid our understanding of variation and development in SLA phonology. 
Note

1. This should not be interpreted to mean that practically no one has reconsidered phonological transfer. Some will be referred to below. Without any claim of completeness, one could also mention James (1983, 1984, 1986) and Wode (1986) among those who have examined phonological transfer from a theoretical point of view. And many of the contributions in Ioup and Weinberger's (1987) anthology on interlanguage phonology naturally involve transfer.

\section{References}

Bialystok, E. - M. Sharwood Smith

1985 "Interlanguage is not a state of mind: an evaluation of the constraint for second-language acquisition", Applied Linguistics 6:101-117.

Donegan, P. J. - D. Stampe

1979 "The study of natural phonology", in: D. A. Dinnsen (ed.), Current Approaches to Phonological Theory. Bloomington IN: Indiana University Press, 126-173.

Dziubalska-Kolaczyk, K.

1987 "Phonological rule typology and second language acquisition", in: A. James - J. Leather (eds.), (1987), 193-205.

Eckman, F.R.

1981a "On the naturalness of interlanguage phonological rules", Language Learning 31:195-216.

Eckman, F.R.

$1981 \mathrm{~b}$ "On predicting phonological difficulty in second language acquisition", Studies in Second Language Acquisition 4:18-30.

Eliasson, $\mathrm{S}$.

1982 "Transfer as evidence for phonological solutions", Studia Anglica Poznaniensia 14:185-196.

Færch, C. - G. Kasper

1980 "Processes and strategies in foreign language learning and communication", Interlanguage Studies Bulletin 5:47-118.

Færch, C. - G. Kasper

1986 “Cognitive dimensions of language transfer", in: E. Kellerman - M. Sharwood Smith (eds.), (1986), 49-65.

Færch, C. - G. Kasper

1987 "Perspectives on language transfer", Applied Linguistics 8:111-136.

Flege, J.E.

1987 "Effects of equivalence classification on the production of foreign language speech sounds", in: A. James - J. Leather (eds.), (1987), 9-39.

Gass, S. M. - L. Selinker (eds.)

1983/ Language Transfer in Language Learning. Rowley MA: Newbury

1992 House, 1983. Revised ed. 1992, Amsterdam: John Benjamins. 
Hammarberg, B.

1985 "Learnability and learner strategies in second language syntax and phonology", in: K. Hyltenstam - M. Pienemann (eds.), Modelling and Assessing Second Language Acquisition. Clevedon: Multilingual Matters, 153-175.

Hammarberg, B.

1988 Studien zur Phonologie des Zweitsprachenerwerbs (Acta Universitatis Stockholmiensis. Stockholmer Germanistische Forschungen 38). Stockholm: Almqvist \& Wiksell International.

Ioup, G. - S. G. Weinberger (eds.)

1987 Interlanguage Phonology: The Acquisition of a Second Language Sound System. Cambridge MA: Newbury House.

James, A.

1983 "Transferability and dialect phonology: Swabian-English", in: A. James

- B. Kettemann (eds.), Dialektphonologie und Fremdsprachenerwerb/Dialect Phonology and Foreign Language Acquisition. Tübingen: Narr, 173-197.

James, A.

1984 "Phonic transfer: The structural bases of interlingual assessments", in: M. van den Broecke - A. Cohen (eds.), Proceedings of the Tenth International Congress of Phonetic Sciences. Dordrecht: Foris, 691-695.

James, A.

1986 "Phonic transfer and phonological explanation: some theoretical and methodological issues", in: E. Kellerman - M. Sharwood Smith (eds.), (1986), 134-149.

James, A. - J. Leather (eds.)

1987 Sound Patterns in Second Language Acquisition. Dordrecht and Providence: Foris Publications.

Kellerman, E. - M. Sharwood Smith (eds.)

1986 Crosslinguistic Influence in Second Language Acquisition. New York: Pergamon.

Linell, $\mathrm{P}$.

1979 Psychological Reality in Phonology: a Theoretical Study. Cambridge:

Maddieson, I.

Cambridge University Press.

1984 Patterns of Sounds. Cambridge: Cambridge University Press.

Major, R.C.

1987 “The natural phonology of second language acquisition", in: A. James - J. Leather (eds.), (1987), 207-224.

Odlin, T.

1989 Language Transfer. Cross-Linguistic Influence in Language Learning. Cambridge: Cambridge University Press.

Ringbom, $\mathrm{H}$.

1987 The Role of First Language in Foreign Language Learning. Clevedon: Multilingual Matters.

Rubach, J.

1984 "Rule typology and phonological interference", in: S. Eliasson (ed.), Theoretical Issues in Contrastive Phonology. Heidelberg: Groos, 37-50. 
Schachter, J.

1983 "A new account of language transfer”, in: S. Gass - L. Selinker (eds.), (1983), 98-111.

Sharwood Smith, M.

1986 "The competence/control model, crosslinguistic influence and the creation of new grammars", in E. Kellerman and M. Sharwood Smith (eds.), (1986), 10-20.

Weinreich, U.

1953 Languages in Contact. The Hague: Mouton.

Wode, $\mathrm{H}$.

1981 Learning a Second Language: An Integrated View of Acquisition. Tü-

Wode, $\mathrm{H}$. bingen: Narr.

1986 "Language transfer: a cognitive, functional and developmental view", in: E. Kellerman - M. Sharwood Smith (eds.), (1986), 173-185.

Wurzel, W.U.

1981 "Phonologie: Segmentale Struktur", in: E. E. Heidolph - W. Flämig - W. Motsch et al. (eds.), Grundzüge einer deutschen Grammatik. Berlin: Akademie-Verlag, chapter 7. 